\title{
A GIS-BASED OPTIMIZATION TECHNIQUE FOR SPATIAL LOCATION OF MUNICIPAL WASTE BINS IN A DEVELOPING CITY
}

\author{
*Aremu, A. S., Adeleke, O. O. and Sule, B. F. \\ DOI:http://dx.doi.org/10.4314/ejesm.v4i3.9
}

Received August $16^{\text {th }}$ 2011; accepted October $26^{\text {th }} 2011$

\begin{abstract}
Prime spatial features such as environmental constraints and indigenous transit routes which determine optimal waste bin locations in developing areas are often neglected. In this study, we illustrate a technique that includes these features to determine the optimal locations of waste bins for case study in Ilorin, Nigeria. The built-in solver for p-median problems in the Geographic information system (GIS)based package; TransCAD v. 5.0 was used to determine the optimal locations of one to ten waste bins. This optimization technique requires less computational time and the output of ten computer runs showed that partial service coverage was obtained when $p=1$ to 5 while full service coverage was achieved with $p \geq 6$. Also the GIS optimized waste bin locations tend to be more accessible to waste generators than the empirical waste bin locations. Hence, this technique has the potential to improve service coverage and public satisfaction in developing areas.
\end{abstract}

Keywords: Municipal solid waste; Geographic information system; waste bin; optimal location; developing city.

\section{Introduction}

Over the years, the spatial organization and existing infrastructure of cities in developing countries pose challenges for sustainable solid waste management programs. Much of the problem arises because the urban spatial structure is characterized by high density, unplanned settlements, limited road access, and ever increasing rural-urban migration (Cohen, 2006). Consequently, these urban centers are major attractions for the location of private and public facilities which require strategic spatial decision support. The science of locating a facility otherwise referred to as a facility location problem, has attracted much attention over the last four decades (Farahani and Hekmatfar, 2009). There are three general types of facility location problems (Miller and Shaw, 2001):

c) Median problems (minisum): the location of facilities to minimize the total or average travel cost between demand locations and facilities. a) Center problems (minimax problems): the location of facilities so as to minimize the maximum travel that any customer will travel to a facility and,

b) Requirement problems: the location of facilities according to some pre specified performance standard.

The median problem is specifically relevant in solving waste bin location problems which is usually to minimize distance between waste generation points and service points. Hence, as a median problem, minimum travel cost is substituted with distance and waste generation points can then be allocated to waste bins. A location-allocation problem is a variant of the facility location problem which includes the assignment of demand locations to the facilities, taking into account certain constraints. Location-allocation models have been widely used for solving decision problems involving siting of emergency service systems, communication networks, distribution systems, and other social facilities (Handler and Mirchandani, 1979). 
Oppong (1996) cited examples of how locationallocation models have contributed significantly to spatial decision making in developing countries. The contributions were mainly within the context of facilities that provide social services such as potable water, healthcare, education, sanitation and security. However, the facility location process may require the processing of huge amount of spatial data and with Geographic Information System (GIS), it is possible to process these data in short time (Mohd Din et al., 2008).

Spatial modeling in GIS offers one approach for solving facility location that service some kind of demand distributed in space. Several GIS software packages such as ArcInfo and TransCAD contain input database and algorithms for spatial analysis of location-allocation problems. Some algorithms employ the $p$-median model whose objective is to minimize sum of distances or costs to a facility. Basically, the $p$-median problem is a minisum location-allocation model that simultaneously sites a pre-specified number of facilities and allocates customers to those facilities (Hillsman, 1984). In the context of solid waste management, the $p$-median problem sites $p$ waste bins among a set of $m$ potential service points along a network to serve $n$ waste generation points.

Applications of GIS for the location of municipal waste bins have been reported in literature. Kao and Lin (2002) demonstrated the efficiency of using computerized geo-referenced data and three location models for the selection of appropriate numbers and locations of waste collection depots. Data for the study came from aerial photographs and GIS, while ArcView 3.0 ${ }^{10}$ was used to process demand points and location data. The results of the study showed that the solution by Shortest Service Location model produced more efficient results; however, it took longer computational time to obtain the solution. Anwar (2006) applied GIS to model how much area is covered by a waste bin at varying walking distances. An ArcView Network Analyst and PC ArcInfo 3.5.1 Technology was used to define the service areas. The GIS analysis after several trials resulted in the optimum distribution of waste bins, an optimized walking distance and a greater efficiency in service coverage. A GIS based algorithm considering the $p$-median constrained model, was applied by Vijay et al. (2008) to identify the optimized location and number of storage bins. The shortest distance having descending slope was used as criteria for selection of optimal waste bin locations. The algorithm had to be rerun several times in order to satisfy aesthetic and environmental factors.

The aforementioned studies have shown that location modeling in GIS environment is an efficient way to improve service coverage and efficiency in municipal solid waste management. However, if some generalized spatial conditions in developing cities are not considered, the results of locationallocation analyses may be misleading. For example, indigenous pathways within the built environment in developing countries are normally the shortest transit route and taking the minimum distance along paved or unpaved roads as the constraint may grossly impair results. Hence, the paramount factors that determine the location of a waste bin are environmental constraints and walking distance to the service point. In this study, we have included these factors and applied TransCAD; a software that fully integrates GIS with location-allocation modeling, for spatial location of municipal waste bins. The application of this technique is illustrated for a case study in the developing city of Ilorin, North Central Nigeria.

\section{Methodology}

The GIS-based optimization technique was applied to a typical part of Ilorin metropolis, Kwara State, Nigeria. The study area is bounded by latitude $8^{\circ} 28^{\prime} 45^{\prime \prime}$ and $8^{\circ} 28^{\prime} 55^{\prime \prime}$ North, and longitude $4^{\circ} 32^{\prime} 50^{\prime \prime}$ and $4^{\circ} 33^{\prime} 20^{\prime \prime}$ East. The satellite image of the study area was scanned in A4 size JPEG image and imported into GIS in DXF format. The digitization process begins with data coding, which is the process of converting spatially located features to geometric objects (points, lines or polygons). Table 1 shows spatial features and their representation in GIS database. Spatial features which are not related to the study were deleted from the map.

A service point is a designated position where a waste bin is placed so that waste generators can empty their wastes while the service area is regarded as the expected coverage of a particular waste bin. The use of GIS to locate the position of waste bins is based on convenient distance to households, 
maximum service coverage and consideration of physical and socio-cultural context of the service area. Waste bins are located at the shoulders of roads after eliminating unsuitable areas and by considering the following constraints.

- $30 \mathrm{~m}$ distance away from environmental sensitive areas such as rivers and streams.

- $30 \mathrm{~m}$ distance away from infrastructural sensitive areas such as bus stops and intersections

- $10 \mathrm{~m}$ distance away from property fence and entrance.

- $20 \mathrm{~m}$ shoulder space for vehicle maneuvering during ingress to and egress from service point.

A buffer was created for these constraints. This gives a platform to identify the potential service points where a waste bin could be placed. The processed information was stored in a spatial database which is a combination of vector spatial data and attributes data with unique identifier for the referenced spatial objects. The Facility Location Function in the GIS package; TransCAD v. 5.0 (Figure 1) was used to solve the $p$-median problem. The "client" represents the waste generation point; the "facility" represents the waste bin while the "cost" is the distance between the waste generation point and the waste bin. The solution to the problem is for the model to generate the best location(s) for waste $\operatorname{bin}(\mathrm{s})$, out of potential service points, with minimum sum of distance from generation points to the waste bin(s). The value of $p$ was taken from 1 to 10 (placing 1-10 waste bins within case study) and the attribute table for each solution was exported for analysis.

\section{Results and Discussion}

The digitized map of the study area is shown in Figure 2. A total of 187 waste generation points were identified within the case study area including 113 residential buildings, 30 commercial buildings, and 44 mixed dwellings. Figure 3 shows the potential waste bin locations which are confined to the shoulders of the accessible road network after creating blockades for unsuitable sites.
A total of 269 potential waste bin locations were identified along the road network. The layers containing these features, their Euclidean distance and the value of $p$ were entered for each computer run using the Facility Location Function in TransCAD software. From the output of each computer run, the spatial performance of the waste bins was measured in terms of the percentage of waste generation points served within $200 \mathrm{~m}$ walking distance. It was observed (Figure 4) that the number of waste generation points served was $50.27 \%$ when $p=1$ and improved gradually to $99.47 \%$ when $p=5$. For values of $p$ greater than 5, 100\% service coverage was achieved. For illustration, Figure 5 shows the optimal locations of six waste bins and the service area of each waste bin. It can be seen that the whole 187 waste generation points are covered by the waste bins. The number of waste generation points within each range of walking distance to the waste bin is presented in Table 2. The walking distance to the waste bins decreased and the service areas were more compact as the value of $p$ increased. More so, majority of waste generation points fell within 51-100m walking range when $p=8,9$ and 10 .

A comparison between empirical waste bin locations and GIS optimized waste bin locations for $p=10$, is shown in Figure 6 . The GIS optimized waste bin locations tend to be more accessible to waste generators than the empirical waste bin locations. For example, $30 \%$ and $55 \%$ of waste generation points were within $0-50 \mathrm{~m}$ and $51-100 \mathrm{~m}$ walking distance to the waste bins respectively in the GIS optimized waste bin locations. On the other hand only $16 \%$ and $44 \%$ of waste generation points were within the same walking distance ranges respectively in the empirical waste bin locations.

\section{Conclusion}

This study presents a simple and rapid technique for spatial location of municipal waste bins in a developing city using TranCAD software. The paramount factors that determine the location of a waste bin are environmental constraints and minimum walking distance. Hence the present study created a buffer for environmental sensitive areas and included foot paths which are common transit routes in developing cities. The analysis of the attribute table from the result of TransCAD 
software showed that the number of waste generation points served within $200 \mathrm{~m}$ walking distance improved as the number of waste bins was increased. However, partial coverage was obtained when $\mathrm{p}=1,2,3,4$ and 5 while $100 \%$ service coverage was achieved with $p=6-10$. A comparison between empirical waste bin location and GIS optimized waste bin location for $p=10$, showed that the GIS optimized waste bin locations tend to be more accessible to waste generators than the empirical waste bin locations. Further analyses of the result of this study could assist municipal solid waste management authorities in developing countries to determine parameters such as level of acceptability of service, waste bin utility, frequency of collection, and cost for provision and collection of waste bins.

\section{Acknowledgements}

The authors acknowledge the support of Dr. Joni Downs of the Department of Geography, University of South Florida, U.S.A., who made the TransCAD software available. The tutelage of Prof. James Mihelcic of the Department of Civil and Environmental Engineering, University of South Florida, U.S.A, is appreciated. The authors also thank the U.S Department of State; sponsor of the Fulbright Junior Staff Development program for their financial support to the lead author.

\section{References}

Anwar, S. M. (2006). Solid Waste Management and GIS: A Case from Kalabagan Area of Dhaka city, Bangladesh. An unpublished M.Phil Thesis, Department of Geography, Norwegian University of Science and Technology, Trondheim, Norway. Accessed from www.sma-bd.com.
Cohen, B. (2006). Urbanization in Developing Countries: Current Trends, Future Projections, and Key Challenges for Sustainability. Technology in Society, 28, 63-80.

Farahani, R. Z. and Hekmatfar, M. (2009). Facility Location: Concepts, Models, Algorithms and Case Studies. Physica-Verlag, Heidelberg, Germany. Handler, G.Y. and Mirchandani, P.B. (1979). Location on Networks: Theory and Algorithms. M.I.T. Press, Cambridge, MA.

Hillsman, E. L. (1984). The $p$-Median Structure as a Unified Linear Model for Location-Allocation Analysis. Environment and Planning, 16, 305-318. Kao, J. and Lin, T. (2002). Shortest Service Location Model for Planning Waste Pickup Locations. Journal of Air and Waste Management Association, 52, 585-592.

Miller, H.J. and Shaw, S.L. (2001). Geographic Information Systems for Transportation: Principles and Applications. Oxford University Press, New York.

Mohd Din, M. A., Wan Jaafar, W., Obot, M. M., Wan Hussin, W. A. (2008). How GIS can be a Useful Tool to Deal with Landfill Site Selection. $<$ http://wgrass.media.osaka-cu.ac.jp/gisideas08/ viewpaper.php?id=269>.

Oppong, J. R. (1996). Accommodating the Rainy Season in Third World Location-Allocation Applications. Socio-Economic Planning Science, 30 (2), 121-137.

Vijay, R., Gautam, A., Kalamdhad, A., Gupta, A., and Devotta, S. (2008). GIS-based Locational Analysis of Collection Bins in Municipal Solid Waste Management Systems. Journal of Environmental Engineering and Science, 7(1), 3943. 


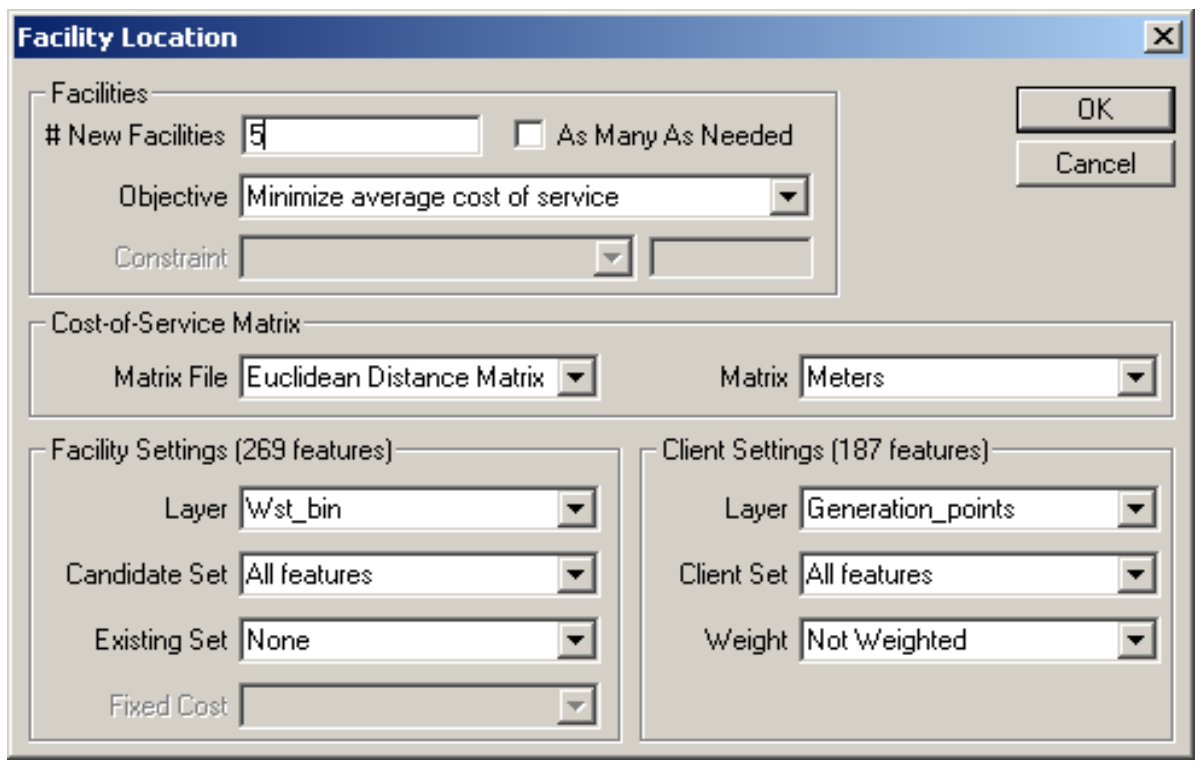

Fig. 1: Facility location function in TransCAD software



Fig. 2: Digitized map of the case study showing solid waste generation points and the road network 


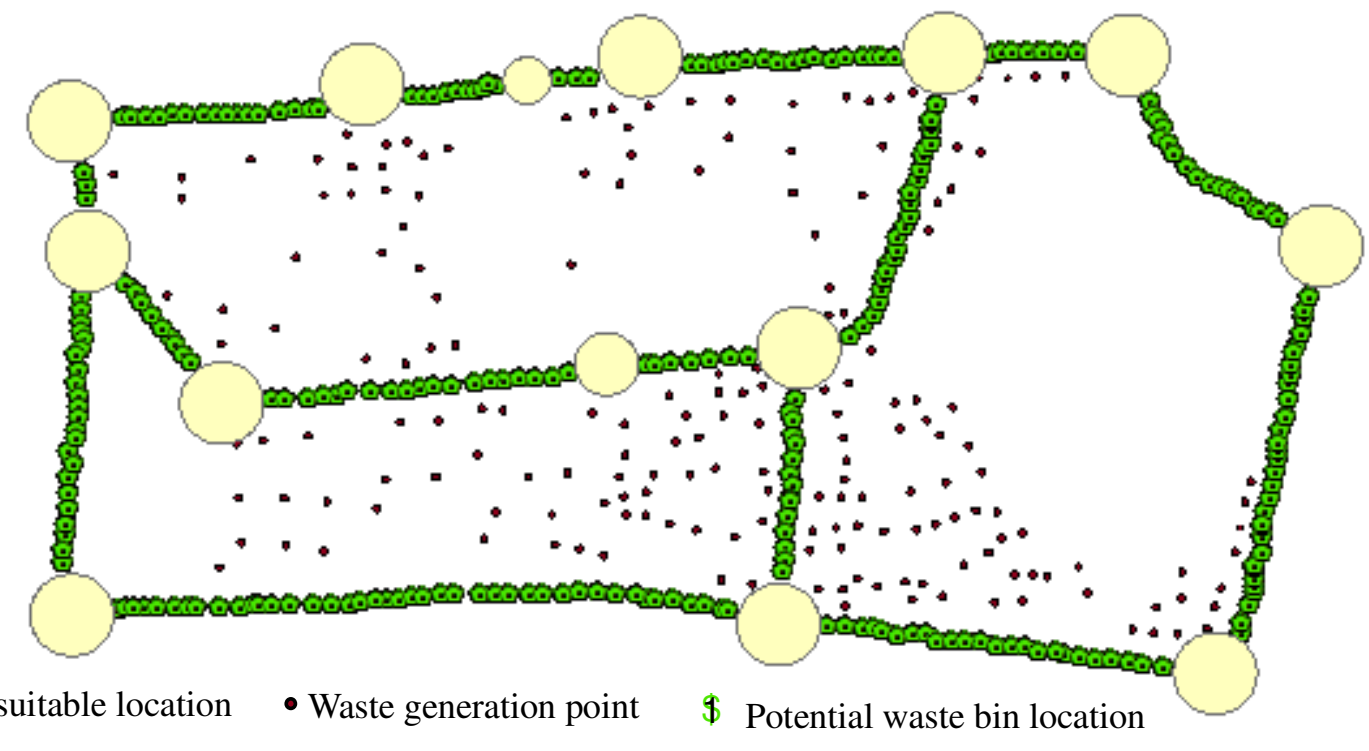

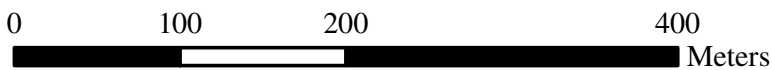

Fig. 3: Potential service points (waste bin locations) along the road network

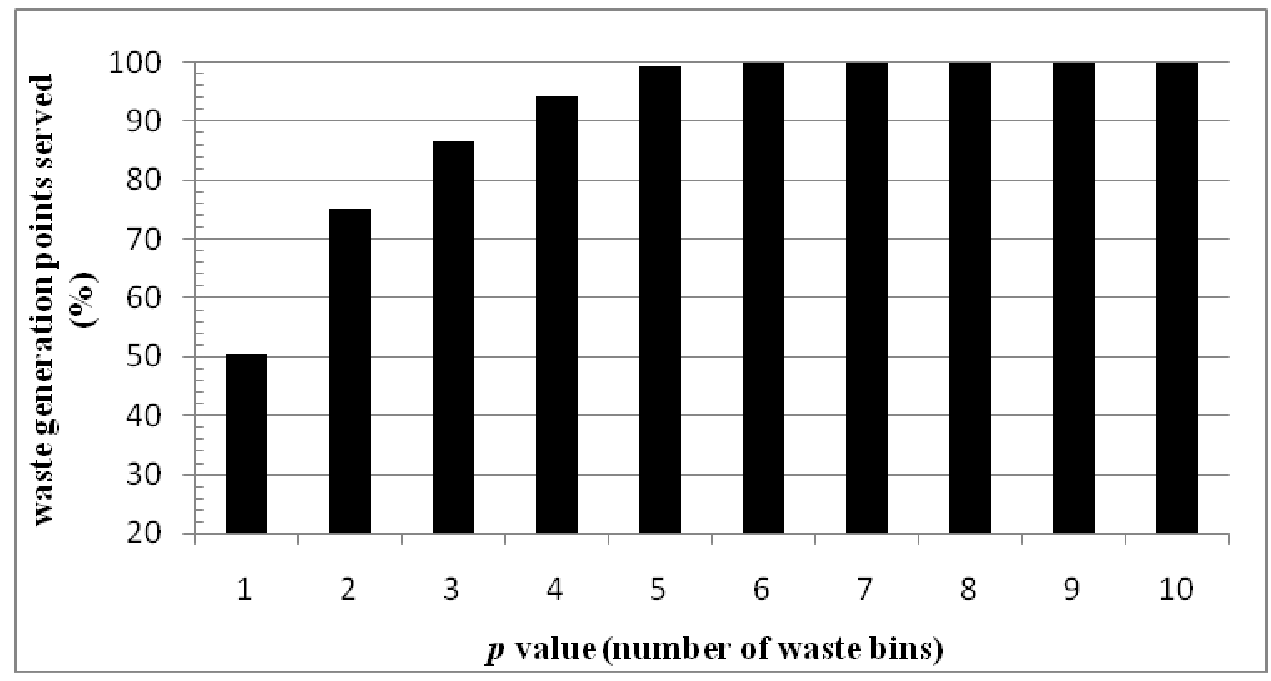

Fig. 4: Spatial performance of waste bins for $p=1$ to 10 




Fig. 5: Optimized location of waste bins for $p=6$ and waste generation points covered by each waste bin

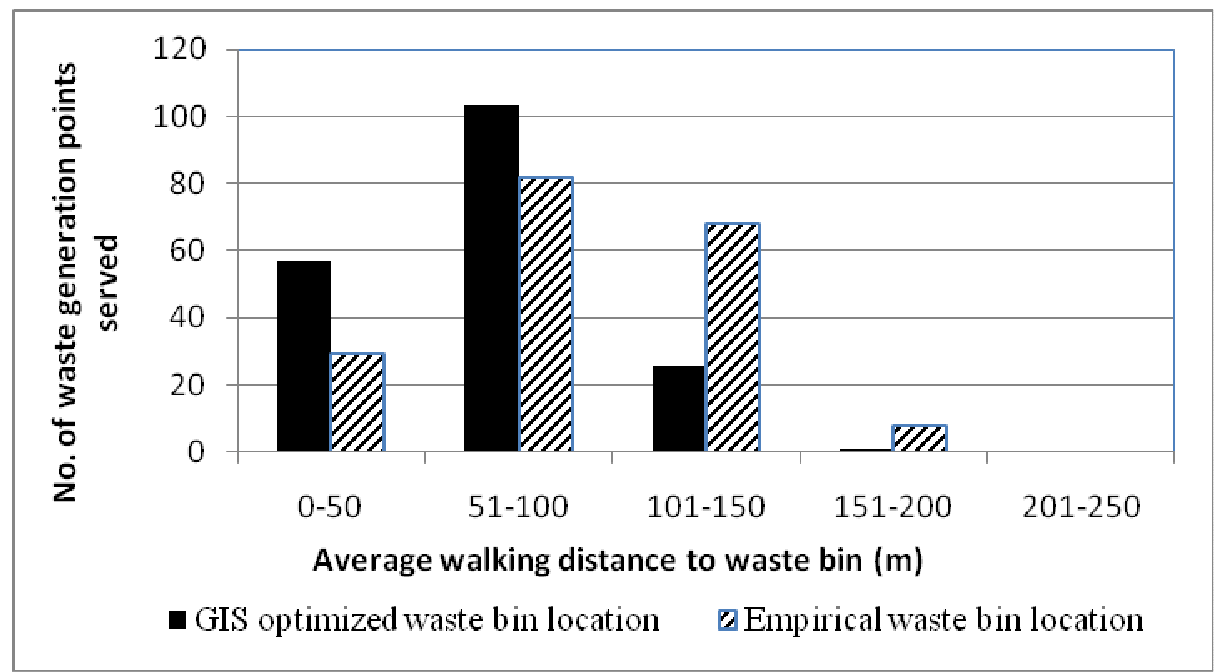

Fig. 6: Number of waste generation points within walking distance ranges for GIS optimized waste bin locations and empirical waste bin locations

\begin{tabular}{ll} 
Table 1 Spatial features and their & representation in GIS \\
\hline Spatial feature & Representation \\
\hline Household & Point \\
Commercial building & Point \\
Mixed dwelling & Point \\
Waste bin & Point \\
Road network/ foot path & Line/arc \\
\hline
\end{tabular}


Table 2 Number of waste generation points within each range of walking distance to the waste bin

\begin{tabular}{|c|c|c|c|c|c|c|c|c|c|c|}
\hline No. of bins & 1 & 2 & 3 & 4 & 5 & 6 & 7 & 8 & 9 & 10 \\
\hline $\begin{array}{l}\text { Walking } \\
\text { distance to } \\
\text { waste bin (m) }\end{array}$ & & \multicolumn{9}{|c|}{ No. of solid waste generation points covered } \\
\hline $0-50$ & 10 & 16 & 17 & 28 & 33 & 37 & 46 & 42 & 51 & 57 \\
\hline $51-100$ & 28 & 41 & 53 & 65 & 74 & 78 & 76 & 105 & 103 & 103 \\
\hline $101-150$ & 31 & 52 & 62 & 61 & 59 & 63 & 56 & 37 & 30 & 26 \\
\hline $151-200$ & 25 & 31 & 30 & 22 & 20 & 9 & 9 & 3 & 3 & 1 \\
\hline $201-250$ & 27 & 26 & 20 & 10 & 1 & 0 & 0 & 0 & 0 & 0 \\
\hline $251-300$ & 14 & 8 & 4 & 1 & 0 & 0 & 0 & 0 & 0 & 0 \\
\hline $301-350$ & 19 & 12 & 1 & 0 & 0 & 0 & 0 & 0 & 0 & 0 \\
\hline $351-400$ & 18 & 1 & 0 & 0 & 0 & 0 & 0 & 0 & 0 & 0 \\
\hline $401-450$ & 9 & 0 & 0 & 0 & 0 & 0 & 0 & 0 & 0 & 0 \\
\hline $451-500$ & 5 & 0 & 0 & 0 & 0 & 0 & 0 & 0 & 0 & 0 \\
\hline $501-550$ & 1 & 0 & 0 & 0 & 0 & 0 & 0 & 0 & 0 & 0 \\
\hline
\end{tabular}

